\title{
ENERXÍA EÓLICA E DESENVOLVEMENTO LOCAL EN GALICIA: OS PARQUES EÓLICOS
}

SINGULARES MUNICIPAIS

Damián COPENA RODRÍGUEZ, decopena@uvigo.es Xavier SIMÓN FERNÁNDEZ,

FCEE, Lagoas-Marcosende s/ n, 36310, Vigo (Pontevedra)

Resumo: A enerxía eólica aparece sinalada na literatura como unha oportunidade para 0 desenvolvemento local. Nese senso, a propiedade local dos parques eólicos amósase como un dos impactos económicos máis destacados. No caso galego a normativa deseñada limitou a propiedade local das centrais eólicas aos municipios e a instalacións de pequena potencia desenvolvidas a partir de unha figura específica da normativa eólica autonómica: os parques eólicos singulares. Neste contexto, este artigo analiza para o caso galego, territorio onde a enerxía eólica ten alcanzado unha grande expansión nas últimas décadas, a propiedade local dos parques eólicos. Para poder realizar esta análise emprégase a información contida na Base de Información Socioeconómica da Enerxía Eólica en Galicia con dous obxectivos: estudar a normativa e o proceso de desenvolvemento dos parques eólicos de propiedade municipal e analizar os impactos económicos locais que se están derivando a partir desta figura eólica específica e o seu posible impacto no desenvolvemento local.

\section{Wind energy and rural development in Galicia: Singular wind farms of municipalities}

Abstract: In scientific literature wind energy is indicated as an opportunity for local development. In this scenario, local ownership of wind farms is one of the most important economic impacts of this energy source. In the Galician case, the designed regulation limited the local ownership of wind power stations to the municipalities and small power facilities developed from a specific figure of the autonomic wind power regulations: singular wind farms. In this context, this article analyses for the Galician case, territory where wind power has reached a great expansion in the last decades, the local property of the wind farms. In order to carry out this analysis, the information contained in the Socioeconomic Information Base of Wind Energy in Galicia is used with two objectives: to study the regulations and the process of development of the municipal wind farms and to analyse the local economic impacts that are being derived from this specific wind farm and its possible impact on local development.

Palabras chave: Enerxía eólica, desenvolvemento local, políticas públicas, parques eólicos singulares, Galicia.

Keywords: Wind energy, local development, public policies, singular wind farms, Galicia.

\section{Introdución}

A enerxía eólica tense desenvolvido rapidamente en Galicia. Desde o primeiro Decreto autonómico do ano 1995 ate a actualidade, instaláronse no territorio galego cerca de 4.100 aeroxeradores, en máis de 150 parques eólicos, que representan unha potencia superior aos 3.300 MW en funcionamento (Copena, 2015). Estas instalacións renovables xeran impactos económicos nos territorios tanto a nivel autonómico (Varela e Sánchez, 2015) como a nivel local (del Río e Burguillo, 2009). A vinculación directa entre enerxías renovables e o desenvolvemento local aparece tamén reflectida especificamente nos documentos normativos que promoven esta clase de producións enerxéticas (IDAE, 2011; Xunta de Galicia, 2000), podendo interpretalo como unha das razóns que levaron aos gobernos a apostar por este tipo de actividades industriais.

Esta relación entre enerxía eólica e desenvolvemento local foi estudada en diferentes traballos científicos (Munday et al., 2011; Slattery et al., 2011) para outros territorios, 
pero nunca antes para o caso galego. Isto é o que se pretende realizar neste traballo, desde dúas vertentes diferentes. Por unha banda, a implantación de centrais de enerxía eólica se localiza principalmente en áreas rurais con potencialidade no recurso eólico. Estas áreas en Galicia soen ser espazos economicamente deprimidos que contan con importantes problemáticas socioeconómicas, polo que as centrais eólicas poden favorecer 0 desenvolvemento local e a dinamización dos espazos xeográficos rurais (Munday et al., 2011; Delicado et al., 2015). Por outra banda, a cuantificación e análise dos impactos locais derivados das centrais renovables constitúe un elemento fundamental para o deseño de futuras políticas públicas que traten de maximizar os obxectivos de primeira orde para os diferentes niveis de goberno: o desenvolvemento local e a instalación de centrais de enerxía renovable.

Un dos principais impactos locais que aparece reflectido na literatura para a enerxía eólica consiste na propiedade local dos aeroxeradores, tal e como sucede en Dinamarca, Inglaterra, Alemaña ou USA (McLaren, 2007; Nolden, 2013; Yin, 2013) onde os axentes locais poden desenvolver de xeito cooperativo parques eólicos. Para o caso galego a propiedade local dos aeroxeradores ate o momento estivo limitada a un axente, os concellos, e a instalacións de pequena potencia desenvolvidas ao amparo de unha figura específica da normativa autonómica, os Parques Eólicos Singulares cuxa propiedade é fundamentalmente dos concellos. Partindo deste contexto, o presente traballo ten dous obxectivos: En primeiro lugar caracterizar a normativa e o proceso de desenvolvemento dos parques eólicos de propiedade municipal e, pola outra, analizar os impactos económicos locais que se están derivando a partir desta figura eólica específica e o seu posible impacto no desenvolvemento local.

O desenvolvemento de esta investigación precisou do emprego de diversa información recompilada na Base de Información Socioeconómica da Enerxía Eólica en Galicia (BISEEGA), ferramenta metodolóxica específica para a análise social e económica da enerxía eólica en Galicia (Copena, 2015) e que posibilita, entre outras cuestións, a análise dos procesos de dos impactos derivados dos parques eólicos singulares municipais.

Para alcanzar o obxectivo analítico sinalado, este traballo divídese da seguinte forma. En primeiro lugar ocupámonos de contextualizar o debate existente na literatura científica no tocante á vinculación entre a enerxía eólica e o desenvolvemento local. En segundo lugar. A continuación preséntase a metodoloxía utilizada no traballo de investigación. Posteriormente, no apartado cuarto, abórdase tanto o marco normativo que regula aos parques eólicos singulares en Galicia como o proceso de desenvolvemento dos mesmos. No seguinte epígrafe analízanse os impactos económicos xerados polos PES de ámbito municipal a partir das facturacións e dos mecanismos de concesión existentes nas centrais en funcionamento e o papel no desenvolvemento local. Finalmente, o artigo remata coa presentación das principais conclusións do traballo de investigación.

\section{Enerxía eólica e desenvolvemento local}

As vinculacións positivas entre a enerxías renovables e o desenvolvemento local teñen sido contempladas na lexislación desenvolvida por múltiples ámbitos de goberno. Neste senso, diferentes normas de ámbito europeo teñen sinalado as potencialidades das fontes enerxéticas renovables. Así, na Directiva 2009/28/CE afírmase que as políticas públicas determinan que a maior utilización da enerxía procedente de fontes renovables pode desempeñar un papel importante para ofrecer oportunidades de emprego e desenvolvemento rexional, especialmente en zonas rurais e ailladas. No mesmo senso, a normativa autonómica e estatal indican que o desenvolvemento das enerxías renovables ten unha influencia positiva no progreso da economía local, pois aproveita recursos naturais endóxenos cunha elevada participación de recursos empresariais e humanos 
(Xunta de Galicia, 2000; IDAE, 2011). Polo tanto, á hora de deseñar as políticas de fomento das enerxías renovables, cómpre tomar en consideración as posibles repercusións positivas sobre o potencial de desenvolvemento rexional e local.

No ámbito científico, a análise dos impactos económicos locais derivados da implantación das centrais renovables ten experimentado un crecente interese nos últimos anos (Collins et al., 2012; Munday et al., 2011; Groth e Vogt, 2014). Certamente, tal e como sinalan Munday et al. (2011), o desenvolvemento a gran escala de tecnoloxías renovables pode traer consigo cambios económicos significativos a nivel local. Neste senso, con frecuencia se indica que as fontes de enerxía renovables teñen un gran potencial para contribuír ao desenvolvemento sostible dos territorios específicos, proporcionándolles unha ampla variedade de beneficios socioeconómicos (del Río e Burguillo, 2009). Sen embargo, os posibles beneficios e impactos positivos para o ámbito local derivados da implantación eólica poden estar comprometidos polo feito de que os procesos sexan liderados por empresas nacionais e internacionais con escasa propiedade local dos equipamentos e da enerxía producida (Delicado et al., 2015). Esta circunstancia é xustamente a que acontece no territorio galego, onde unhas poucas empresas privadas e alleas ao ámbito local, concentran a práctica totalidade da potencia en funcionamento (Regueiro, 2011a). A cuestión é relevante, xa que o impacto económico dun proxecto de produción de enerxía eólica varía a nivel local, dependendo de quen posúe a instalación, de quen desenvolve o proxecto e de como foi este proceso (Breukers e Wolsink, 2007). Dese xeito, en función do marco normativo existente, das políticas públicas deseñadas, as posibilidades para os axentes e os impactos económicos derivados das centrais serán diferentes para o ámbito local. Así, por exemplo, noutros lugares do mundo, as entidades municipais participan directamente no negocio eólico xerado ao recibir aportacións directas derivadas da facturación dos parques eólicos que están nos seus termos municipais. Sirvan como exemplos Grecia e Portugal. No primeiro destínase unha porcentaxe do 3\% da facturación dos parques eólicos para as entidades municipais (Dimitropoulos e Kontoleon, 2009) e no caso de Portugal a porcentaxe para as entidades locais é do 2,5\% (Nadaï et al., 2010). Estas porcentaxes directas da facturación dos parques eólicos supoñen, evidentemente, un incremento dos ingresos directos para as arcas municipais.

Noutros países fomentouse normativamente o desenvolvemento de parques eólicos comunitarios, tal e como acontece en Dinamarca, Inglaterra, Alemaña ou USA (McLaren, 2007; Nolden, 2013; Yin, 2013). Nestes lugares os propietarios dos terreos e as comunidades locais poden promover e desenvolver, de xeito cooperativo e comunitario, un proxecto de parque eólico. Sen embargo, no caso galego, o marco regulador deseñado imposibilitou a creación de parques eólicos comunitarios. Efectivamente, a opción de propiedade das centrais eólicas por parte dos axentes locais soamente resulta posible para os municipios e está limitada a unha figura específica do marco regulador da enerxía eólica galega, os PES municipais, que aparecen pois como a única oportunidade factible de desenvolver directamente un parque eólico de propiedade local por parte dos concellos.

A propiedade pública municipal dos parques eólicos aparece como un elemento que vai permitir a obtención de rendas locais derivadas da implantación das centrais renovables. Así, neste contexto normativo, o establecemento de medidas para o fomento da propiedade municipal dos parques eólicos emerxe como unha oportunidade económica para incrementar as rendas das arcas municipais a partir do aproveitamento dun recurso endóxeno local e renovable como é o vento e que, no caso galego, vincúlase tamén coa autosuficiencia enerxética. Este ámbito, tal e como sinalan Liebe et al. (2017), permite aos municipios xerar ingresos fiscais adicionais, o que pode ser relevante en tempos de diminución dos ingresos públicos debido a razóns económicas ou sociodemográficas, 
especialmente en zonas rurais que contan con problemáticas sociais, económicas e ambientais relevantes, tal e como acontece no territorio galego. Nese senso, Hvelplund et al. (2013) sinalan que debería de promoverse a propiedade maioritaria local dos parques eólicos, xa que isto aumentaría a aceptación da enerxía eólica debido a que unha parte importante dos ingresos iría ate as comunidades locais e rexionais onde se localizan os aeroxeradores.

En definitiva, a implantación de centrais eólicas vincúlase directamente co desenvolvemento local, sendo a propiedade municipal dos parques eólicos unha oportunidade de interese para a xeración de rendas que incrementen a capacidade económica dos concellos, especialmente nas áreas rurais.

\section{Metodoloxía}

O presente traballo de investigación empregou un enfoque multimetodolóxico baseado do uso de diferentes metodoloxías e métodos cuantitativos e cualitativos para a análise (Waddington, 2004; McKim, 2015). Para o proceso de recompilación da información necesaria seguíronse as pautas dos procesos de triangulación (Ramsay, 1998), que consisten na utilización de unha ampla gama de elementos, cualitativos e cuantitativos, para abordar a comprensión do funcionamento dun sistema social. Esta investigación vinculase coa información existente na Base de Información Socioeconómica da Enerxía Eólica en Galicia (BISEEGA), ferramenta metodolóxica específica para a análise social e económica da enerxía eólica en Galicia (Copena, 2015).

A partir de diversas metodoloxías, entre as que destacan as vinculadas coa investigación participativa (Cassell e Symon, 2004), e diferentes procesos de investigación foi posible a creación da BISEEGA, que está desenvolvida polo Grupo de Investigación en Economía Ecolóxica e Agroecoloxía da Universidade de Vigo e ten coma obxectivo caracterizar o proceso de implantación territorial e enerxética dos parques eólicos no territorio galego e as súas consecuencias sociais e económicas a diferentes escalas territoriais (desde o nivel do conxunto de Galicia ate o nivel local).

Para o traballo concreto de análise dos PES municipais e dos seus impactos, empregouse información dispoñible en varias das subbases da BISEEGA. Así, grazas a un seguimento exhaustivo dos procedementos administrativos dos parques eólicos singulares púidose coñecer o proceso de implantación e as dinámicas dos PES municipais (Subbase Socioadministrativa dos parques eólicos de Galicia). Por outra banda, mediante a recompilación dos dados de produción, eficiencia e prezo de venda da enerxía eólica producida, alén do coñecemento dos procesos de licitación e concesión establecidos para as centrais, foi posible estimar os impactos económicos directos derivados dos PES municipais en funcionamento no territorio galego (Subbase Económica dos parques eólicos en Galicia e Subbase de rendas públicas locais dos parques eólicos de Galicia).

A información inserida na BISEEGA, acadada a partir das metodoloxías anteriormente sinaladas, compleméntase no presente texto coa utilización de ferramentas vinculadas cos Sistemas de Información Xeográfica que favoreceron a realización de análises territoriais e a xeoreferenciación dos concellos con PES municipais en diferentes situación administrativa o que permitiu a súa análise xeográfica.

\section{Marco regulador e desenvolvemento dos parques eólicos singulares municipais}

Galicia ten sido unha Comunidade Autónoma pioneira na regulación da implantación das enerxías renovables no seu territorio, algo que acontece tanto para a enerxía eólica (Simón e Copena, 2012) como no relativo á produción de electricidade a partir da biomasa forestal (Copena e Simón, 2014). O Goberno autonómico galego desenvolveu, a partir das 
competencias coas que conta no ámbito das enerxías renovables, o pioneiro Decreto 205/1995 e o posterior Decreto 302/ 2001 para regular os procesos de autorización de parques eólicos. O modelo de desenvolvemento deseñado nestas normas apostou prioritariamente polo desenvolvemento de parques eólicos ligados a grandes empresas privadas, maioritariamente multinacionais, mediante a figura dos Plans Eólicos Empresariais ou Estratéxicos (Montero et al., 2010). Neste modelo os axentes rurais (labregos e gandeiros, sindicatos agrarios, entidades profesionais do mundo rural, empresas locais, etc) e as entidades municipais (Concellos, Mancomunidades e Deputacións) quedaron nun segundo plano tanto no referido á decisión sobre a instalación de parques eólicos como no relativo á planificación enerxética.

Os impactos económicos locais quedaron polo tanto vinculados á participación das empresas locais nalgunha das fases de execución dos parques, á contratación de traballadores locais para as tarefas de desenvolvemento e execución dos parques (Regueiro, 2011b) e á participación que os propietarios dos terreos eólicos tiñan no negocio eólico, ben mediante unha renda anual ou ben mediante un pagamento nunha única vez mediante, a compra ou expropiación dos terreos eólicos (Copena, 2015).

De todos os axentes locais que nomeamos, somentes os concellos contaron coa posibilidade limitada de desenvolvemento de parques eólicos a partir da figura dos Parques Eólicos Singulares (PES), aprobada dentro do Decreto 302/20011, novidosa a nivel estatal e que posibilitaba e fomentaba a propiedade pública municipal de pequenas centrais renovables. Esta clase específica de parques eólicos estaba pensada, principalmente, para alcanzar os obxectivos de (i) estar "destinado principalmente ó autoconsumo da enerxía producida nel, que poderá ser municipal, doméstico, industrial ou de servicios"; (ii) alcanzar unha produtividade mínima, fixada en termos de 2.400 horas equivalentes; e, indirectamente, (iii) xerar impactos económicos positivos nos concellos afectados mediante procesos industrias (iv) xerar impactos directos para nas arcas municipais. Os PES contan con outra singularidade adicional que os diferencia do resto de parques eólicos galegos e que está vinculada coa implantación territorial. Concretamente, esta clase de instalacións desvincúlase da planificación territorial existente para a eólica a través do Plan Sectorial Eólico de Galicia polo que se favorece a instalación en espazos alleos á planificación territorial eólica, o que aparece como un elemento favorable para a súa expansión.

A creación desta figura específica e a posibilidade de desenvolver un parque eólico que tivese como promotor á propia entidade local foi recibida con interese por un importante número de concellos. Certamente, nas poucas convocatorias que se desenvolveron para a selección de PES municipais, os concellos presentaron numerosos proxectos para tratar de desenvolver centrais singulares nas súas localidades: polo menos 182 concellos, o $62 \%$ do total, presentaron as súas propostas ás convocatorias anuais desenvolvidas ao abeiro do Decreto 302/ 2001, tal e como aparece reflectido no mapa seguinte.

Figura 1: Concellos que presentaron proxecto de PES municipal ás convocatorias anuais.

1 O desenvolvemento normativo dos PES municipais, iniciado co Decreto 302/2001, complétase mediante a Orde do 29 de outubro de 2002 pola que se determinan os requisitos para a autorización de parques eólicos singulares. O Decreto 242/2007, do 13 de decembro, polo que se regula 0 aproveitamento da enerxía eólica en Galicia derrogou o Decreto 302/ 2001 e, polo tanto, a propia figura dos parques eólicos singulares, aínda que os que estaban en tramitación administrativa continuaron (e continúan) co proceso. 


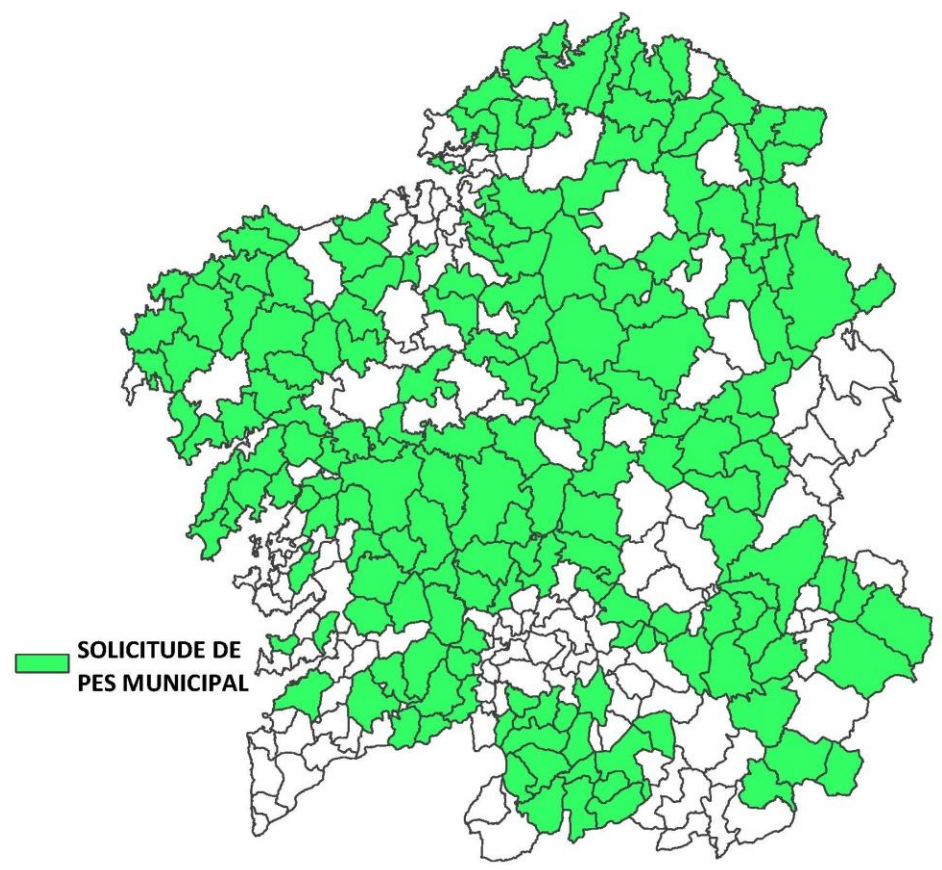

Fonte: Elaboración propia a partir do Diario Oficial de Galicia mediante ferramentas SIX.

Podemos cualificar este feito como un rotundo éxito da figura deseñada polo goberno galego. Os concellos galegos, moitos deles axentes pasivos no profundo proceso de desenvolvemento eólico empresarial que levaba ocorrendo nos seus territorios nos anos anteriores, observaron unha boa oportunidade para xerar novas rendas locais contribuíndo ao mesmo tempo a producir enerxía limpa que loitaba contra o cambio climático, tal e como podemos derivar da información cualitativa recollida na BISEEGA.

Sen embargo, houbo diversos elementos limitantes que impediron unha maior "democratización" do negocio eólico en Galicia a partir da propiedade local das centrais eólicas. O primeiro elemento estaba xa contido na propia normativa reguladora dos PES ao fixar unha limitación de potencia máxima de 3 MW para cada proxecto de parque eólico. Nun País que tiña admitidos a trámite a principios da década pasada máis de 3.000 MW e nos que a maioría dos parques eólicos se situaban en potencias entre 30 e 50 MW, un parque eólico de 3 MW sempre sería algo cando menos anecdótico. Aínda así, se a totalidade das peticións municipais acabaran cristalizando en parques eólicos de propiedade municipal, os concellos si poderían terse convertido nun axente importante na produción de enerxía renovable en Galicia. Mais, como veremos a continuación, tampouco foi así.

O deseño do proceso de implantación dos PES vinculaba a obtención de dereitos á selección de anteproxectos en convocatorias anuais nas que o goberno galego establecía límites absolutos de potencia máxima a admitir a trámite. A primeira convocatoria para os PES tivo lugar en outono do ano 2002 e fixaba inicialmente unha potencia máxima prevista para o conxunto de PES (non só os municipais) de $25 \mathrm{MW}$, posteriormente ampliada ata os $50 \mathrm{MW}$. Houbo 79 concellos con interese en desenvolver un PES, sumando 204,25 MW de potencia. No verán de 2003 resólvese esta primeira convocatoria para os 
PES² admitindo a trámite un total de 16 proxectos de PES municipais. Na seguinte convocatoria $^{3}$ ocorreu exactamente o mesmo: pouca potencia ofertada inicialmente (25 MW), ampliación posterior (a 50 MW), moitas solicitudes de concellos (106) e un número final de 21 proxectos admitidos a trámite computando por unha potencia total de 47,65 MW. É importante non perder de vista o resultado final destas dúas primeiras convocatorias: 37 PES municipais e 87,85 MW xa que se corresponde coa potencia con algún grado de desenvolvemento administrativo aínda a día de hoxe

Chegárase a esta situación en 2004, nun ano previo a unhas eleccións autonómicas que se antollaban moi disputadas e con algunha posibilidade de mudar no goberno da Xunta despois de 16 anos de maiorías absolutas do partido conservador despois do episodio do goberno do partido socialista. Este contexto é importante para entender o que ocorreu nese momento en relacións aos PES. O goberno galego mudou a súa estratexia e, nun afán de contentar a moitos concellos, non o podemos entender de outra forma dados os antecedentes que vimos comentando, decidiu a finais de $2004^{4}$ ofertar inicialmente de 100 MW, potencia posteriormente ampliada a 307 MW5. Nesta convocatoria presentáronse propostas por parte de 153 concellos dos que foron seleccionados 114 proxectos cunha potencia acumulada de 271,75 MW6. É dicir, 3 veces máis potencia que o sumatorio das dúas convocatorias anteriores.

Entre as dúas primeiras convocatorias e esta terceira, o total de potencia asignada aos concellos foi de 359,6 MW, unha cifra moi importante que representaría arredor do 10,7\% do total de potencia en funcionamento no ano 2017 se se tivesen desenvolvido o conxunto de centrais municipais admitidas a tramitación. Sen embargo, as cousas non funcionaron así e xurdiu un problema insalvable: a inseguridade xurídica que provocaron aquelas presas de última hora dun goberno que tiña medo a perder as eleccións, e que perdeu finalmente, e un novo goberno que fixo da enerxía eólica unha das súas bandeiras. Esa inseguridade xurídica substanciase nun proceso de anulación da convocatoria express de 2004 iniciado en 2007 en nunha posterior sentenza de 2009 que anula o realizado en 2007.

Como consecuencia destes factores, os parques eólicos singulares en Galicia non alcanzan unha dimensión global de importancia malia as expectativas que se xeraron a partir do interese experimentado polas entidades municipais. Xa que logo, o obxectivo da "democratización" do negocio eólico non se alcanzou na súa totalidade e os impactos económicos no medio local tampouco son de envergadura, a pesares da existencia de unha bolsa de MW de PES que se atopan autorizados ou admitidos a trámite e que teñen posibilidades de seren desenvolvidos nos vindeiros anos. Como veremos posteriormente, esta afirmación do escaso impacto dos PES municipais a nivel local require ser matizada

\footnotetext{
2 Resolución do 14 de xullo de 2003 pola que se publica a relación de solicitudes de autorización para a instalación de parques eólicos singulares admitidas a trámite ó abeiro da Orde do 29 de outubro de 2002.

3 Mediante a Orde do 22 de xaneiro de 2004 pola que se abre o prazo para a presentación de solicitudes de autorización para a instalación de parques eólicos.

4 Coa publicación da Orde do 17 de decembro de 2004 pola que se abre o prazo para presentación de solicitudes de autorización para a instalación de parques eólicos singulares.

${ }_{5}^{5}$ Mediante a Orde do 23 de maio de 2005 pola que se modifica a Orde do 17 de decembro de 2004 pola que se abre o prazo para presentación de solicitudes de autorización para a instalación de parques eólicos singulares.

${ }^{6}$ Resolución do 26 de xullo de 2004 pola que se publica a relación de solicitudes de autorización para a instalación de parques eólicos singulares admitidas a trámite ao abeiro da Orde do 22 de xaneiro de 2004 e súa modificación do 20 de abril de 2004.
} 
no contexto territorial de cada PES e de cada Concello, pero para a totalidade do País os PES municipais non son, por moito, uns axentes importantes no mapa eólico galego, como se pode observar claramente no seguinte cadro.

Táboa 2: Caracterización dos PES municipais en Galicia a maio de 2017.

$\begin{array}{lcccc}\text { Situación dos PES Municipais } & \begin{array}{c}\text { No } \\ \text { de } \\ \text { PES }\end{array} & \begin{array}{c}\text { Potencia } \\ \text { (MW) }\end{array} & \begin{array}{c}\text { \% dos PES } \\ \text { municipais respecto } \\ \text { da potencia eólica } \\ \text { total }\end{array} & \begin{array}{c}\text { Potencia media } \\ \text { da instalación } \\ \text { (MW) }\end{array} \\ \text { En funcionamento } & 13 & 34,80 & 1,04 & 2,68 \\ \text { Autorizados } & 9 & 24,35 & 2,82 & 2,71 \\ \text { Admitidos a trámite } & 16 & 32,20 & 1,29 & 2,01\end{array}$

Fonte: Elaboración propia a partir de BISEEGA, Diario Oficial de Galicia e METAD

Figura 2: Caracterización xeográfica segundo a situación administrativa dos PES municipais en Galicia. Maio de 2017.

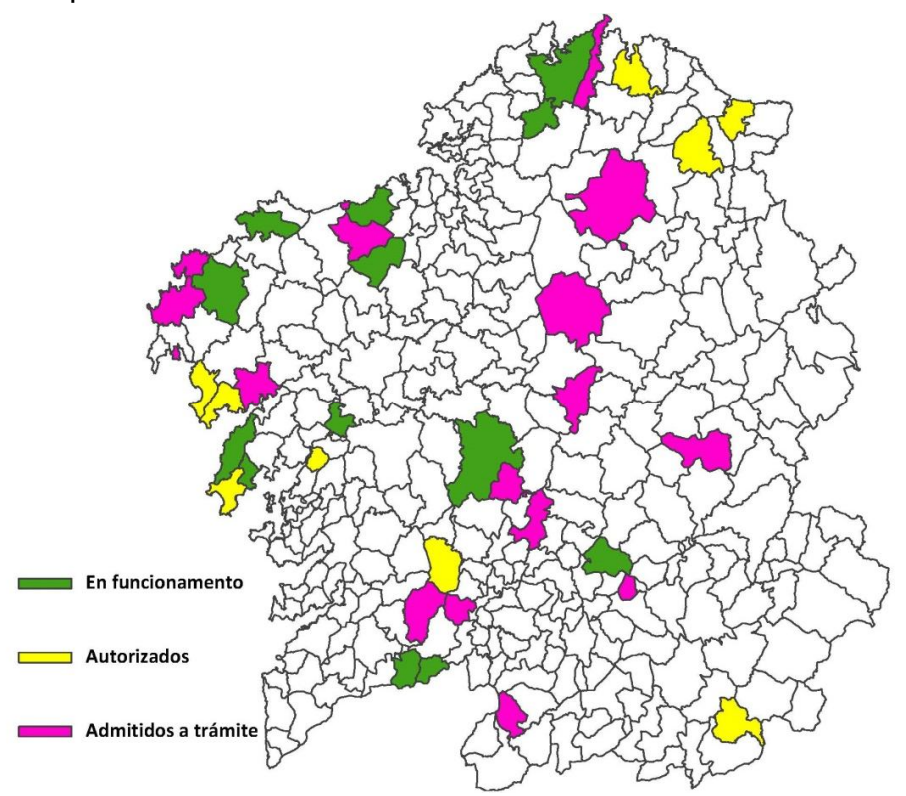

Fonte:

Elaboración propia mediante ferramentas SIX a partir de BISEEGA, Diario Oficial de Galicia e METAD

$\mathrm{Na}$ actualidade hai, por tanto, 13 PES municipais en funcionamento con 25 aeroxeradores asociados que suman unha potencia de $34,80 \mathrm{MW}$, o que equivale apenas ao 1,04\% dos MW totais con acta de posta en marcha no territorio galego. Pola súa banda, os PES de concellos autorizados son un total de 9 cunha potencia agregada de 24,35 MW, o 2,82\% da potencia total autorizada. Finalmente, as instalacións singulares municipais admitidas a trámite, debido á anulación das resolucións e o retrotaemento dos procedementos das convocatorias previas, son 16 centrais cunha potencia acumulada de 32,20 MW. Aínda así, cómpre salientar que os procesos administrativos dos parques singulares de concellos en tramitación continúan, a pesar do tempo transcorrido desde as convocatorias, lentamente o seu avance con recentes autorizacións nos últimos meses?.

7 Como exemplo podemos sinalar a recente autorización do PES de Mondoñedo mediante a Resolución do 14 de outubro de 2014, da Dirección Xeral de Enerxía e Minas, pola que se fai público 
Táboa 3: Caracterización dos PES municipais en funcionamento a maio de 2017.

\begin{tabular}{|l|l|c|c|c|}
\hline \multicolumn{1}{|c|}{ Concello promotor } & \multicolumn{1}{|c|}{$\begin{array}{c}\text { Nome do parque } \\
\text { eólico singular }\end{array}$} & $\begin{array}{c}\text { Potencia } \\
\text { (MW) }\end{array}$ & $\begin{array}{c}\text { Numero de } \\
\text { aerox. }\end{array}$ & $\begin{array}{c}\text { Potencia unitaria } \\
\text { aerox. (kW) }\end{array}$ \\
\hline Padrón & PES Padrón & 1,70 & 2 & 850 \\
\hline Vimianzo & PES O Barrigoso & 3,00 & 2 & 1.500 \\
\hline Ponteceso & PES Monte da Barda & 3,00 & 2 & 1.500 \\
\hline As Somozas & PES Monte das Augas & 3,00 & 1 & 3.000 \\
\hline Arbo & PES Arbo & 2,70 & 2 & 1.500 \\
\hline Lalín & PES Lalín & 3,00 & 4 & 750 \\
\hline Ortigueira & PES Ortigueira & 2,90 & 2 & $2.000 ; 900$ \\
\hline As Neves & PES As Neves & 2,40 & 3 & 800 \\
\hline Arteixo & PES Arteixo & 2,00 & 1 & 2.000 \\
\hline A Pobra do Caramiñal & PES Pobra do Caramiñal & 3,00 & 1 & 3.000 \\
\hline Porto do Son & PES Porto do Son & 3,00 & 1 & $1.670^{8}$ \\
\hline Cerceda & 2,55 & 2 & $2.000 ; 850^{9}$ \\
\hline Nogueira de Ramuín & PES Cerceda & 2,55 & 2 & \\
\hline \multicolumn{2}{|l|}{ PES Nogueira de Ramuín } & $\mathbf{3 4 , 8 0}$ & & \\
\hline
\end{tabular}

Fonte: Elaboración propia a partir da BISEEGA, DOG e Rexistro administrativo de instalacións de produción de enerxía eléctrica.

Malia a autorización deste parque singular de Mondoñedo, chama a atención a inexistencia de PES municipais con acta de posta en marcha na provincia de Lugo e que só haxa un (o de Nogueira de Ramuín) en funcionamento na provincia de Ourense. A Coruña é claramente a provincia líder neste ámbito, con 9 das 13 centrais eólicas municipais en funcionamento a maio de 2017.

A información que permite caracterizar aos PES municipais, tanto no tocante á distribución xeográfica dos PES segundo a situación administrativa na que se atopan, como o relativo ás principais características das centrais desenvolvidas polas entidades municipais que se encontran en funcionamento no territorio galego a maio de 2017, aparece recollida no mapa e na táboa que se atopan a continuación.

o Acordo do Consello da Xunta do 10 de outubro de 2014 polo que se autorizan as instalacións, se aproba o proxecto de execución e se declara a utilidade pública, en concreto, do parque eólico singular de Mondoñedo, promovido polo Concello de Mondoñedo nos concellos de Mondoñedo e Abadín. Este PES fora admitido a tramitación no ano 2003 coa primeira convocatoria de centrais singulares, polo que a autorización administrativa chega 14 anos despois.

8 Con limitación de potencia para cada aeroxerador de a $1.275 \mathrm{~kW}$ (Resolución de 17 de novembro de 2010, da Dirección Xeral de Industria, Enerxía e Minas, pola que se autoriza, se aproba o proxecto de execución e se recoñece a condición de instalación acollida ao réxime especial de produción de enerxía eléctrica do parque eólico singular de Cerceda, promovido polo concello de Cerceda.

${ }_{9}^{9}$ Con limitación de potencia a con limitación de potencia a $550 \mathrm{~kW}$ (Resolución do 8 de febreiro de 2010 pola que se autorizan as instalacións electromecánicas, se aproba o proxecto de execución, se recoñece a condición de acollida ao réxime especial de produción de enerxía eléctrica, se declara a utilidade pública, en concreto, das instalacións do proxecto do parque eólico singular de Nogueira de Ramuín, promovido polo concello de Nogueira de Ramuín (Ourense), e se declara a compatibilidade do parque eólico singular co permiso de investigación número 4898 Tina. 
Como conclusión a este apartado cabe sinalar que a figura dos PES municipais xerou un grande interese entre os concellos galegos, aínda que diferentes factores como a inseguridade xurídica, provocada polas presas dun goberno débil diante dunhas eleccións e pola politización excesiva das decisións administrativas; as escasas convocatorias anuais realizadas e a lentitude coa que foron avanzaron os procesos administrativo, dificultaron e limitaron o desenvolvemento desta clase de centrais eólicas específicas. Sen embargo, a dia de hoxe existen centrais eólicas singulares en funcionamento no territorio galego que están a xerar impactos económicos locais. No seguinte apartado imos analizar cales son estes impactos e as potencialidades futuras desta clase de instalacións eólicas de propiedade municipal.

\section{Impactos económicos dos parques eólicos singulares municipais}

A análise dos impactos económicos dos parques eólicos singulares desenvolvidos por concellos vainos permitir coñecer a súa limitada incidencia sobre o medio rural no que se asentan. Esta circunstancia tense producido por diversas razóns vinculadas co marco normativo e co desenvolvemento da implantación desta figura eólica específica

A primeira das motivacións que explica o escaso impacto dos PES a nivel local ten que ver coa escasa dimensión global destes parques, como xa mencionamos anteriormente. A pesar de que entre os PES en funcionamento encontramos tres dos parque eólicos máis modernos que hai no territorio galego (ao contaren cos únicos aeroxeradores de $3000 \mathrm{~kW}$ instalados ${ }^{10}$ ), a súa limitada potencia, nunca superior aos $3 \mathrm{MW}$, e o seu escaso e lento desenvolvemento (despois de 15 anos de existencia da figura existen soamente 34,08 MW en funcionamento, representando o $1,04 \%$ do total de potencia instalada en Galicia), provocan que os resultados económicos dos parques eólicos singulares sexan bastante modestos.

Desde a BISSEGA estimáronse esas cifras individuais e globais que se xeran a partir da posta en funcionamento das centrais singulares. Coñecida a produción de cada parque eólico singular ${ }^{11}$ e o prezo media anual de venda de enerxía ${ }^{12}$, estimáronse as facturacións anuais desagregadas destas instalacións eólicas municipais. Como se pode observar nos datos do anexo 1, os PES son centrais moi eficientes tecnoloxicamente, xa que se exceptuamos os anos iniciais, con producións baixas debido aos necesarios axustes técnicos ou a períodos de funcionamento que non alcanzan a totalidade do ano, as eficiencias enerxéticas destes parques (medidas en horas de producións equivalentes) encóntranse entre as máis elevadas de toda Galicia. Cómpre salientar especialmente aos parques de Barrigoso no concello de Vimianzo e o de Ponte da Barda en Ponteceso, cada un con máis de 3.000 horas de funcionamento en varios dos anos que comprende 0 período de análise. Estas cifras sobrepasan claramente a media das centrais galegas que foi de cerca de 2.250 no ano 2011 (CNMC, 2016). A alta produtividade das centrais eólicas municipais traduciuse tamén en facturacións relativamente elevadas que roldaron nalgúns anos, a pesares das potencias tan reducidas por parque, o millón de euros.

10 Son os parques eólicos singulares de Monte das Augas (Concello de As Somozas), A Pobra do Caramiñal e Porto do Son.

11 Desgraciadamente, so é posible coñecer o dato de produción desagregada de centrais eólicas ata 0 ano 2011, xa que a partir dese ano o Ministerio de Enerxía, Turismo e Axenda Dixital (METAD) deixou de publicar eses datos.

12 Que subministra a Comisión Nacional dos Mercados e da Competencia a través do "Informe mensual de ventas de energía de fuentes de energía renovables, cogeneración y residuos". 
Coñecida a facturación anual de cada un dos PES en funcionamento, realizamos tamén unha estimación da produción do conxunto dos parques eólicos singulares tendo en conta o ano no que cada instalación obtén a acta de posta en marcha. Así, estimouse a facturación anual dos PES a partir das medias de produción do conxunto dos parques eólicos galegos e do prezo medio de venda das producións obtidas. Como era de agardar, desde o ano 2005, no que comeza a funcionar a primeira instalación singular, ate 0 ano 2015 as facturacións anuais dos PES municipais galegos van incrementándose gradualmente coa entrada de novas instalacións acadando o máximo de facturación anual no ano 2013 con máis de 7,6 millóns de euros. A facturación bruta acumulada estimada para a totalidade dos PES de concellos galegos no período temporal sinalado é de máis de 45 millóns de euros.

Que parte desa cantidade fica en mans dos Concellos? Cal é o impacto económico das centrais singulares para as arcas municipais? A resposta a esta pregunta atopámola ao analizar as fórmulas escollidas para a xestións dos parques eólicos e os condicionantes existentes en cada caso particular. O marco normativo permite tres posibilidades de xestión para os PES municipais: concesión administrativa a unha empresa externa, creación dunha empresa mixta e desenvolvemento da central eólica por medios propios. A totalidade dos Concellos dos que dispomos de información escolleron a fórmula da concesión administrativa a un terceiro, polo que as entidades municipais verán condicionadas as súas rendas segundo a natureza dos acordos tomados nos respectivos órganos de contratación. Na BISEEGA hai información recompilada para 8 procesos de licitación de PES municipal o que nos permite analizar os mecanismos de pagamento acordados e comparar os resultados económicos para as arcas municipais. Co obxecto de poder realizar comparacións entre as centrais eólicas que contan con diferentes potencias instaladas, as contías brutas que perciben os concellos lévanse a unha unidade comparativa ( $€ / M W)$. Así, os diferentes pagamentos derivados dos Canons Fixos e dos Canons Variables dos parques singulares en funcionamento aparecen recollidos na seguinte táboa.

Táboa 4. Resultados económicos estimados dos PES municipais para os Concellos.

\begin{tabular}{|c|c|c|c|c|c|}
\hline $\begin{array}{c}\text { PES } \\
\text { municipal }\end{array}$ & $\begin{array}{c}\text { Duración } \\
\text { do contrato } \\
\text { (anos) }\end{array}$ & $\begin{array}{c}\text { Canón } \\
\text { Fixo } \\
\text { (€/MW) }\end{array}$ & $\begin{array}{c}\text { Canon Variable } \\
\text { (\% } \\
\text { Facturación) }\end{array}$ & $\begin{array}{c}\text { Canon Variable } \\
\text { estimado } \\
(€ / \text { MW) (ano) }\end{array}$ & $\begin{array}{c}\text { Canon Total } \\
\text { Estimado } \\
\text { (€/ MW) } \\
\text { (ano) }\end{array}$ \\
\hline Cerceda & 20 & 11.765 & $5 \%$ & $7.370(2014)$ & $19.135(2014)$ \\
\hline Padrón & 20 & 28.235 & $10 \%$ & $19.525(2011)$ & $47.760(2011)$ \\
\hline Arbo & 25 & 18.518 & $4,5 \%$ & $9.884(2011)$ & $28.402(2011)$ \\
\hline Ponteceso & 25 & 23.333 & $8 \%$ & $22.427(2010)$ & $45.760(2010)$ \\
\hline Somozas & n.d. & 0 & $20 \%$ & $40.437(2011)$ & $40.437(2011)$ \\
\hline Vimianzo & 20 & 23.333 & $6 \%$ & $17.284(2010)$ & $40.617(2010)$ \\
\hline Lalín & 40 & 0 & $15 \%$ & $29.288(2011)$ & $29.288(2011)$ \\
\hline Ortigueira & 50 & 0 & $20 \%$ & $39.050(2011)$ & $39.050(2011)$ \\
\hline
\end{tabular}

Fonte: Elaboración propia a partir da BISEEGA

13 A información dos Canons está indicada en cada PES municipal en diferentes anos en función , por unha banda, do ano de posta en marcha de cada central (Cerceda comeza a funcionar no ano 2013) e, por outra, da existencia de datos de produción anual desagregada. No caso de parques nos que non existía dato de produción desagregada, esta estimouse para o ano 2011 en base as horas medias dos parques eólicos galegos, agás no caso de Cerceda, xa que comeza a funcionar posteriormente. 
Na táboa constátase, en primeiro lugar, que hai PES municipais nos que o pagamento derívase unicamente de unha porcentaxe da facturación bruta da central eólica. Nos tres casos onde esta é a modalidade escollida para o pagamento, as porcentaxes van desde o 15\% (Lalín) ata o 20\% (Somozas e Ortigueira) ${ }^{14}$. En segundo lugar, os datos coñecidos indican que o mecanismo de obtención de rendas máis habitual nos PES de concellos en funcionamento consiste nun pagamento mixto, cunha parte que vai ser fixa e con outra parte que é variable, dependendo da facturación anual da central. Os canons fixos anuais, levados á unidade comparativa, van desde os 11.765 ata os $28.235 € / \mathrm{MW}$ e os canons variables que forman parte de esta modalidade mixta oscilan entre o $5 \%$ e o $10 \%$ da facturación.

Como se pode observar, os datos recompilados indican unha grande variabilidade nas contías totais dos pagamentos. O mellor resultado obtense para o caso de PES de Padrón. O seu Canon anual Total, resultado dun pagamento mixto con parte fixa e parte variable, alcanzaba unha cantidade estimada de máis de $47.000 € / \mathrm{MW}$ no ano 2011. No outro extremo, o pagamento unitario máis reducido tamén xurde dun modelo mixto, e sitúase en pouco máis de 19.000 euros/ MW, neste caso para o 2014. É dicir, a variabilidade nos canons municipais é do $250 \%$.

Certamente, os beneficios para os concellos dependen da elección do mecanismo de pagamento e das cantidades establecidas derivadas do proceso de licitación. Neste senso, a aposta por cada un dos mecanismos de pagamento posibles ten pros e contras. Por exemplo, a porcentaxe da facturación garante que se a empresa concesionaria ten máis ingresos o concello incrementará os seus beneficios e viceversa. No mesmo senso, a capacidade produtiva agardada para cada instalación tamén terá importancia na decisión, a cal se fará maior cando máis alta sexa a porcentaxe que cobra o concello en función da facturación. Pola contra, un canon fixo non terá en conta as posibles melloras de eficiencia e de produción das instalacións nin a existencia de posibles cambios drásticos no réxime retributivo, cuestión que se está a producir nos últimos anos. A incerteza do réxime retributivo fai que as futuras variacións que se vaian producir poidan repercutir a medio prazo tanto de xeito positivo como negativo nos Canons para os concellos. É dicir, existen unha serie de incertezas relativas ao negocio eólico e ás dinámicas produtivas que impide coñecer con certeza cal é o mellor equilibrio entre a parte fixa e variable do canon. Só se pode dicir que en igualdade de horas de produción canto maiores sexan ambos, loxicamente maior será a retribución que reciban as entidades municipais.

Por outra banda, como se pode observar na táboa 4, as concesións administrativas fixaron períodos de duración cunha alta variabilidade, indo desde os 20 ate os 50 anos. Neste senso cómpre ter en conta que a vida útil dun parque eólico está en torno aos 20 anos. De feito, en Galicia estase comezando a repotenciar centrais eólicas obsoletas tecnoloxicamente a través da normativa específica de repotenciamento (Decreto 138/201015). Descoñecemos, coa información dispoñible, que acontecerá nas previsibles mudanzas de aeroxeradores para as concesións de máis de 20 anos existentes.

Como comentamos previamente, os resultados económicos dos Parques Eólicos Singulares son moi modestos pero son a única fonte de ingresos nas arcas públicas galegas derivados da propiedade de parques eólicos. Estas cifras modestas cambian de traza se

14 Esta modalidade tamén pode contar cun pagamento anual mínimo garantido, tal e como se establece no caso de As Somozas cunha contía anual de 100.000 euros.

15 Decreto 138/ 2010, do 5 de agosto, polo que se establece o procedemento e as condicións técnicoadministrativas para a obtención das autorizacións de proxectos de repotenciación de parques eólicos existentes na Comunidade Autónoma de Galicia. 
comparamos os seus resultados relativos en relación ao que ocorre cos parques eólicos convencionais. A contías unitarias que están a percibir os concellos son moito máis elevadas que outra clase de fluxos de rendas derivados da eólica nas áreas rurais. Por exemplo, os pagamentos que perciben de media os propietarios rurais que contan con terreos onde se instalan parques eólicos roldan os $3.000 € / \mathrm{MW}$ e a porcentaxe que supoñen estas rendas con respecto á facturación bruta sitúase no 1,7\% para o ano 2015 (Copena, 2015). Se comparamos as porcentaxes dos canons municipais galegos co que ocorre noutros países da nosa contorna, a conclusión segue a ser a mesma. As contías relativas dos PES son moi superiores aos porcentaxes que se perciben de xeito directo en Portugal e en Grecia para as entidades municipais (2,5\% e 3\% respectivamente). Pero esta situación débese considerar con prudencia pois as altas porcentaxes agachan unha moi fraca presenza da eólica municipal en Galicia. Por exemplo, no caso portugués unha cámara municipal que conte cun parque de $40 \mathrm{MW}$ de potencia no seu termo municipal podería percibir en torno aos 233.000 euros anuais ${ }^{16}$, contía moi superior aos 150.000 euros de máximo que percibe Ponteceso nalgún ano. No mesmo senso, en Portugal tamén se constata a existencia de Cámaras Municipais que, ademais de percibir a porcentaxe da facturación bruta indicada anteriormente, participan no capital social das empresas. Tal e o caso do municipio de Resende no distrito de Viseu que conta co 15\% do capital social da empresa eólica que desenvolveu un parque eólico na súa localidade ${ }^{17}$.

Finalmente, o carácter modesto das rendas eólicas que reciben os poucos concellos galegos con PES en funcionamento confírmase se realizamos unha análise que relativice estes fluxos de rendas con respecto a outra clase de ingresos municipais. Por exemplo, os 85.000 euros que recibiu Padrón polo seu PES no ano 2011 representan en torno ao 5,7\% dos impostos directos que liquidou esa entidade no mesmo ano ${ }^{18}$. Evidentemente, 0 tamaño do Concello e a capacidade relativa de obtención de ingresos propios dálle maior importancia a estes novos fluxos de renda en casos concretos. É o caso do Concello de Arbo: os ingresos que xera o seu PES, uns 76.000 euros do canon anual total no ano 2011, representan máis do $15 \%$ dos impostos directos, polo que terán unha importancia relativa moi superior ao caso anterior.

Todos os resultados anteriores son derivados de procesos de explotación da enerxía eólica onde o titular do dereito de explotación, o concello neste caso, decide transmitir ese dereito a un terceiro. É dicir, o concello renuncia a exercer directamente a capacidade de posuír un maior control sobre o parque eólico singular e, seguramente, a unhas maiores rendas para a súa economía. Isto é o que ocorre polo menos a nivel de comunidades de propietarios que posúen parques eólicos propios. En Munday et al. (2011) encontramos como unha comunidade de Escocia recibe arredor de $500.000 €$ por un aeroxerador de 2 MW. É dicir, valores moi superiores aos comentados anteriormente para os PES municipais galegos adxudicados a un terceiro.

Os concellos poderían ter apostado pola creación dunha empresa mixta participada polo concello para a explotación da instalación eólica singular ou pola fórmula do desenvolvemento e a xestión do PES municipal mediante medios propios. Ambas opcións están contempladas na lexislación vixente. Que é o que tería acontecido para as arcas

\footnotetext{
16 Esta estimación faise a partir dos datos medios que fornece a Entidade Reguladora dos Serviços Energéticos (ERSE). http:// www.erse.pt

17 Tal e como consta na Acta da sessão ordinária da assembleia municipal de resende, realizada no dia 14 de dezembro do ano de 2006.

18 Os ingresos derivados de impostos directos no concello de Padrón no ano 2011 ascendían a case os 1,5 millóns de euros (https:// presupuestos.gobierto.es/)
} 
locais nestas modalidades? É de agardar que as rendas locais que obterían os Concellos serían máis altas nestes dous últimos casos pois, cando menos, parte do beneficio industrial que agora obteñen as empresas que resultaron adxudicatarias ficaría nas arcas municipais. Resulta de interese constatar que a opción da creación dunha empresa mixta si que se pode materializar no futuro próximo na xestión de algúns PES, xa que foi adoptada por varios concellos con parques en tramitación administrativa, e algúns deles xa autorizados: Así, o concello de Viveiro creou a sociedade Eogal Viveiro ${ }^{19}$, S.L. para o PES de Viveiro; en Carnota, o Concello xunto á promotora eólica Eurovento constituíron a sociedade Carnotavento para o PES desta localidade ${ }^{20}$. Sen embargo, os PES municipais asociados a estas empresas mixtas aínda non puideron conseguir a acta de posta en marcha e a posta en funcionamento. Nos vindeiros anos veremos se se desenvolven estas centrais e cales son os impactos económicos derivados.

Como conclusión a este apartado cabe sinalar que, por unha banda, os limitantes establecidos no relativo á potencia máxima para os PES municipais provocan que estas contías non sexan máis elevadas e, por outra, o escaso nivel de desenvolvemento que obtiveron estas instalacións ate o momento fai que só exista repercusión económica en escasas localidades e que para o conxunto do territorio esta figura poida considerarse como anecdótica, aínda que localmente en determinados casos poida ter relevancia. A comparación con outros casos coñecidos en outros lugares do mundo e cos ingresos derivados dos impostos directos indica que, en xeral, as contías poden considerarse como reducidas. Aínda así, tal e como consta na literatura, a propiedade local das centrais é un ámbito que se está desenvolvendo con éxito noutros lugares do planeta, polo que dentro dos múltiples cambios normativos que se están realizando na lexislación eólica galega, resultaría posible e positivo o establecemento de figuras que avanzasen nesta cuestión. Nese senso, a recuperación da figura dos PES municipais aprendendo das eivas existentes ate o de agora e mellorando normativamente esta clase de centrais podería converterse nunha opción de interese para conseguir que nos vindeiros anos o desenvolvemento eólico galego tivese maior repercusión no desenvolvemento local.

Certamente, a pesares de que a propia normativa galega indica que o desenvolvemento das enerxías renovables ten unha influencia positiva no progreso da economía local (Xunta de Galicia, 2000), o modelo de desenvolvemento eólico predominante, onde unhas poucas empresas privadas concentran grande parte da potencia en funcionamento e onde se apostou principalmente pola figura dos Plans Eólicos Empresariais ou Estratéxicos ligados a empresas privadas limitou a posibilidade do desenvolvemento de parques eólicos de propiedade local a unha figura con potencia limitada e, xa que logo, escasas capacidades para xerar grandes recursos económicos. En definitiva, tal e aconteceu en outros lugares do mundo como Oaxaca (Huesca-Pérez et al., 2016), o marco normativo eólico galego limitou moito as posibilidades dos municipios. Así, os diferentes documentos normativos que regularon e regulan a enerxía eólica galega estableceron un proceso de planificación vertical de arriba cara abaixo, onde os gobernos locais non contaron con capacidades para planificar e decidir sobre a posta en marcha de centrais eólicas só

19 Como exemplo de acordo podemos ver a aprobación dos estatutos que rexerán a sociedade mixta para a instalación e explotación dun parque eólico singular que se pode consultar na Acta da sesión ordinaria celebrada polo pleno do concello de Viveiro do día 17 de agosto do 2004 . http:/ / www.viveiro.es/ backoffice/ file/ 04-08-17-acta-3757.pdf

20 Outros concellos que elixiron este mecanismo son: o concello do Covelo xunto á empresa Engasa, creou Eólica de Covelo, S.L para o PES desa localidade e, por último, o Concello de Catoira xunto a Engasa constituíron a sociedade Enerxía de Catoira, S.L. para o desenvolvemento do PES municipal de Catoira. 
tiveron a posibilidade de desenvolver centrais eólicas singulares de $3 \mathrm{MW}$ que nin sequera, polos motivos anteriormente comentados, acadaron grande repercusión no conxunto do territorio galego.

\section{Conclusións}

Nos últimos anos tense sinalado na literatura científica á enerxía eólica como unha oportunidade para o desenvolvemento local. Nese senso, un dos impactos económicos máis destacados desta fonte enerxética correspóndese coa propiedade local das centrais renovables. No caso galego esta posibilidade estivo soamente permitida para os concellos a partir da implantación de unha figura eólica específica pioneira a nivel estatal que contaba con potencial interese para os municipios galegos denominada parque eólico singular. Esta figura, que nace no ano 2001, agromou de facto como a primeira oportunidade para que os municipios tivesen a posibilidade de ser promotores das centrais eólicas a nivel galego, cunhas condicionantes importantes como unha reducida potencia instalada e a súa vinculación co autoconsumo enerxético.

Tal e como temos comprobado no presente traballo, o xurdimento desta nova figura eólica xerou grande interese por parte dos concellos galegos que participaron nas diferentes convocatorias desenvolvidas ao abeiro do Decreto do que partiu a creación das centrais eólicas singulares. O marco regulador posibilitou de facto autonomía aos concellos á hora de xestionar os PES municipais polo que a figura dos PES municipais concedía potencialidades para a obtención de rendas, sobre todo para os concellos rurais con pouca capacidade para xerar ingresos e con escasa actividade empresarial. Deste xeito, 182 dos concellos galegos, case o 60\% das entidades municipais galegas, solicitaron a aprobación de anteproxectos de PES municipais.

Sen embargo, esta clase de parques singulares para os municipios non tivo a repercusión inicialmente agardada debido, principalmente, ás restricións de potencia marcadas na definición da figura, aos problemas de inseguridade xurídica e á lentitude dos procedementos de autorizacións administrativas das instalacións admitidas a trámite no seu momento. Certamente, este modelo de parques eólicos non tivo a expansión necesaria para que tivese maior repercusión a nivel galego. A Xunta de Galicia non apostou o suficiente por esta clase de centrais que vinculaba a expansión eólica coa propiedade das centrais por parte dos concellos. Deste xeito, entre as escasas convocatorias anuais, os conflitos xudiciais e os cambios retributivos e normativos existentes, só hai na actualidade 13 parques eólicos singulares en funcionamento desenvolvidos por concellos galegos, aínda que existe un conxunto de parques eólicos singulares promovidos por concellos nalgunha fase de tramitación administrativa agardando poder desenvolverse nos vindeiros anos. Aínda así, cabe sinalar que os PES municipais en funcionamento proporcionan contías monetarias para concellos rurais, polo que a súa importancia específica a nivel local pode considerarse como significativa.

Os PES en funcionamento apostaron pola concesión das centrais eólicas a terceiros dos que se derivan ingresos a partir de cantidades que soen combinar pagamentos fixos e variables vinculados cunha porcentaxe da facturación das centrais singulares. A análise dos resultados para os concellos, levados á unidade comparativa $€ / \mathrm{MW}$, amósanos que existen fluxos de renda para as arcas municipais que van desde os $19.000 €$ / MW ate os 47.000 do PES. Estas cantidades son cativas se as comparamos con exemplos de outros lugares do mundo e cos ingresos derivados da imposición municipal e, como temos comprobado no traballo, están moi condicionadas polos límites normativos establecidos á figura eólica e polos mecanismos de xestión escollidos polos gobernos municipais. Aínda así, estes fluxos de renda derivados dos canons anuais totais están a ser relevantes 
localmente en algúns dos concellos rurais que contan con dificultades para xerar ingresos propios.

A aposta pola propiedade pública municipal das centrais eólicas favoreceu nas áreas onde se implantaron os PES municipais un maior reparto dos beneficios derivados da produción renovable entre outros axentes alén das empresas privadas que tiñan conseguido un Plan Eólico Empresarial. Sen embargo, debido á limitación de potencia a un máximo de 3 MW exerceu de importante limitante para as posibles rendas xeradas a nivel local e ao escaso grado de desenvolvemento que acadou esta figura pode considerarse que esta foi unha oportunidade perdida para fortalecer aos concellos rurais a partir dun recurso natural renovable existente nos seus municipios, nun contexto social e económico dificultoso. Se cadra, a figura dos PES municipais pode aínda reinventarse e voltar a aparecer como un modelo de interese para o desenvolvemento da enerxía eólica no territorio galego, favorecendo por unha banda a consecución dos obxectivos de política enerxética e, pola outra, a obtención de rendas que favorezan a dinamización local por parte das administracións municipais. As novas políticas públicas que regulamentarán a produción de electricidade mediante o aproveitamento do vento nos vindeiros anos teñen na súa man mellorar a figura dos PES e conseguir fortalecer as posibilidades de desenvolvemento local dos concellos galegos a partir do aproveitamento dun recurso local e renovable.

\section{Bibliografía}

BREUKERS, S.; WOLSINK, M. (2007): "Wind power implementation in changing institutional landscapes: An international comparison". Energy Policy, 35, pp. 2737-2750.

CASSELL, C.; SYMON, G. (2004): Essential Guide to Qualitative Methods in Organizational Research, Sage Publications, London, Thousand Oaks, New Delhi, pp. 154-164.

COLLINS, A. R.; HANSEN, E; HENDRYX, M. (2012): “Wind versus coal: Comparing the local economic impacts of energy resource development in Appalachia”. Energy Policy, 50, pp. 551-561.

COMISIÓN NACIONAL DE LOS MERCADOSY DE LA COMPETENCIA. (2016): “Información mensual de estadísticas sobre las ventas de régimen especial". https:/ / www.cnmc.es

COPENA RODRÍGUEZ, D. (2015): “Enerxía eólica e medio rural: unha análise aplicada dos impactos socioeconómicos dos parques eólicos no mundo rural galego". Tese de Doutoramento. Universidade de Vigo.

COPENA RODRÍGUEZ, D.; SIMÓN FERNÁNDEZ, X. (2014): "A produción de enerxía eléctrica a partir da biomasa forestal primaria: análise do caso galego". Revista Galega de Economía, 23 (2), pp. 91 112.

CORBELLE RICO, E.; CRECENTE MASEDA, R. (2008). “O abandono de terras: concepto teórico e consecuencias". Revista Galega de Economía, vol. 17, núm. 2, pp. 47-62.

DEL RÍO, P.; BURGUILLO, M. (2009): "An empirical analysis of the impact of renewable energy deployment on local sustainability". Renewable and Sustainable Energy Reviews, 13, pp. 1314-1325.

DELICADO, A.; TRUNINGER, M.; FIGUEIREDO, E.; SILVA, L.; JUNQUEIRA, L.; HORTA, A.; FONSECA, S.; NUNES, M.J.; SOARES, F. (2015): Terras de Sol e de vento: dinâmicas sociotécnicas e aceitação social das energias renováveis em Portugal. 1 a edición. Lisboa: ICS. Imprensa de Ciências Sociais.

DIMITROPOULOS, A.; KONTOLEON, A. (2009): "Assessing the determinants of local acceptability of wind-farm investment: A choice experiment in the Greek Aegean Islands". Energy Policy, 37, pp. 1842-1854.

ESPAÑA. COMISIÓN NACIONAL DA COMISIÓN NACIONAL DOS MERCADOS E A COMPETENCIA. (2016): Informe mensual de ventas de energía de fuentes de energía renovables, cogeneración y residuos. Madrid: Comisión Nacional da Comisión Nacional dos Mercados e a Competencia.

ESPAÑA. INSTITUTO PARA A DIVERSIFICACIÓN E O AFORRO DA ENERXÍA. (2011): Plan de Energías Renovables en España, 2005-2010. http:// www.idae.es/tecnologias/ energias-renovables/plan-deenergias-renovables-2011-2020 
EUROPA. PARLAMENTO EUROPEO (2009): Directiva 2009/28/CE do Parlamento Europeo e do Consello de 23 de abril de 2009 relativa ao fomento do uso de enerxía procedente de fontes renovables e pola que se modifican e se derrogan as Directivas 2001/ 77/ CE e 2003/ 30/ CE. Diario Oficial de la Unión Europea, 5 de xuño de 2009, L 140, páxs. 16-62. http://eurlex.europa.eu/LexUriServ/ LexUriServ.do?uri=0J:L:2009:140:0016:0062:ES:PDF

GALICIA. CONSELLERÍA DE INDUSTRIA E COMERCIO. (2001): Decreto 302/ 2001, do 25 de outubro, polo que se regula o aproveitamento da enerxía eólica na Comunidade Autónoma de Galicia. DOG noㅡ 235 do 5 de Decembro de 2001. Diario Oficial de Galicia, 5 de decembro de 2001, núm. 235, páxs. 15457- 15520.

GROTH, T. M.; VOGT, C. A. (2014): "Rural wind farm development: Social, environmental and economic features important to local residents". Renewable Energy, 63, pp. 1-8.

HUESCA-PÉREZ, M.E., SHEINBAUM-PARDO, C., KÖPPEL, J. (2016): "Social implications of siting wind energy in a disadvantaged region - The case of the Isthmus of Tehuantepec, Mexico". Renewable and Sustainable Energy Reviews, 58, pp. 952-965.

HVELPLUND, F.; BERND MÖLLER, B.; SPERLING, K. (2013): “Local ownership, smart energy systems and better wind power economy". Energy Strategy Reviews, 1, pp. 164-170.

MCKIM, C. A. (2015). The Value of Mixed Methods Research: A Mixed Methods Study. Journal of Mixed Methods Research. Vol. 11 (2), 202-222.

MCLAREN LORING, J. (2007): “Wind energy planning in England, Wales and Denmark: Factors influencing project success". Energy Policy, 35, pp. 2648-2660.

MONTERO, M.; SIMÓN, X.; GIMÉNEZ, E.L; CASTRO, F. (2010): "Os Plans Eólicos Empresariais en Galicia. Unha análise do seu desenvolvemento". Revista Galega de Economía, 19 (1), pp. 101-128.

MUNDAY, M.; BRISTOW, G.; COWELL, R. (2011): "Wind farms in rural areas: How far do community benefits from wind farms represent a local economic development opportunity?". Journal of Rural Studies, 27, pp. 1 - 12.

NADAII, A.; KRAUSS, W.; AFONSO, A.I.; DRACKLÉ, D.; HINKELBEIN, O.; LABUSSIÈRE, O.; MENDES, C. (2010): "El paisaje y la transición energética: comparando el surgimiento de paisajes de energía eólica en Francia, Alemania y Portugal". Nimbus, 25-26, pp. 155-173.

NOLDEN, C. (2013): "Governing community energy-Feed-in tariffs and the development of community wind energy schemes in the United Kingdom and Germany". Energy Policy, 63, pp. 543552.

REGUEIRO FERREIRA, R. M. (2011a): A propiedade do vento galego: o desenvolvemento do sector eólico en Galiza (1995-2011). Bertamiráns, Ames: Edicións Laiovento.

REGUEIRO FERREIRA, R. M. (2011b): El negocio eólico. La realidad del empleo, promotores y terrenos eólicos. Madrid: Libros de la catarata.

SIMÓN FERNÁNDEZ, X.; COPENA RODRÍGUEZ, D. (2012): “Eolic energy and Rural Development: an analysis for Galicia”. Spanish Journal of Rural Development, 3 (3), pp. 13-28.

SLATTERY, M. C.; LANTZ, E.; JOHNSON, B. L. (2011): "State and local economic impacts from wind energy projects: Texas case study”. Energy Policy, 39 (12), pp. 7930-7940.

VARELA VÁZQUEZ, P.; SÁNCHEZ CARREIRA, M.C. (2015): "Socioeconomic impact of wind energy on peripheral regions". Renewable and Sustainable Energy Reviews, 50, pp. 982-990.

WADDINGTON, D. (2004). "Participant observation”. Cassell, C., Symon, G (Eds.), Essential Guide to Qualitative Methods in Organizational Research. London: Sage Publications. Páxs. 154-164.

XUNTA DE GALICIA. (2000): Libro Branco da Enerxía. Instituto Enerxético de Galicia: Santiago de Compostela. http:// www.inega.es/ descargas/publicacions/ 45-d-Libro Branco.pdf

YIN, Y. (2013): "An analysis of empirical cases of community wind in Oregon". Renewable and Sustainable Energy Reviews, 17, pp. 54-73. 


\section{ANEXO I}

Táboa: Caracterización económico-produtiva de varios dos PES municipais en funcionamento.

\begin{tabular}{|c|c|c|c|c|c|c|c|c|c|}
\hline $\begin{array}{l}\text { Concello } \\
\text { do PESM }\end{array}$ & $\begin{array}{r}\text { Pot. } \\
\text { (M } \\
\text { W) }\end{array}$ & Datos & 2005 & 2006 & 2007 & 2008 & 2009 & 2010 & 2011 \\
\hline \multirow[t]{3}{*}{ Padrón } & \multirow[t]{3}{*}{1,7} & $\begin{array}{l}\text { Produción } \\
\text { (MWh) }\end{array}$ & 1.335 & 3.885 & 4.200 & 3.756 & 3.856 & 4.657 & 3.893 \\
\hline & & $\begin{array}{l}\text { Estim. } \\
\text { Facturac. (€) }\end{array}$ & $\begin{array}{c}116.9 \\
33\end{array}$ & $\begin{array}{c}352.7 \\
63\end{array}$ & $\begin{array}{c}328.2 \\
49\end{array}$ & $\begin{array}{c}378.92 \\
7\end{array}$ & $\begin{array}{c}310.4 \\
09\end{array}$ & $\begin{array}{c}363.3 \\
19\end{array}$ & $\begin{array}{c}340.1 \\
03\end{array}$ \\
\hline & & $\begin{array}{l}\text { Estimación } \\
\text { HPE }\end{array}$ & 785 & 2.285 & 2.471 & 2.209 & 2.268 & 2.739 & 2.290 \\
\hline \multirow[t]{3}{*}{$\begin{array}{c}\text { Vimianz } \\
0\end{array}$} & \multirow[t]{3}{*}{3} & $\begin{array}{l}\text { Produción } \\
\text { (MWh) }\end{array}$ & 3.309 & 8.908 & 7.940 & 10.340 & $\begin{array}{c}10.27 \\
7\end{array}$ & $\begin{array}{c}11.07 \\
7\end{array}$ & S.D. \\
\hline & & $\begin{array}{l}\text { Estim. } \\
\text { Facturac. (€) }\end{array}$ & $\begin{array}{c}289.8 \\
35\end{array}$ & $\begin{array}{c}808.8 \\
58\end{array}$ & $\begin{array}{c}620.5 \\
47\end{array}$ & $\begin{array}{c}1.043 .1 \\
59\end{array}$ & $\begin{array}{c}827.3 \\
01\end{array}$ & $\begin{array}{c}864.1 \\
79\end{array}$ & S.D. \\
\hline & & $\begin{array}{l}\text { Estimación } \\
\text { HPE }\end{array}$ & 1.103 & 2.969 & 2.647 & 3.447 & 3.426 & 3.692 & S.D. \\
\hline \multirow[t]{3}{*}{$\begin{array}{c}\text { Pontece } \\
\text { so }\end{array}$} & \multirow[t]{3}{*}{3} & $\begin{array}{l}\text { Produción } \\
\text { (MWh) }\end{array}$ & & 8.127 & 8.487 & 9.179 & 9.794 & $\begin{array}{c}10.78 \\
0\end{array}$ & S.D. \\
\hline & & $\begin{array}{l}\text { Estim. } \\
\text { Facturac. }(€)\end{array}$ & & $\begin{array}{c}737.9 \\
42\end{array}$ & $\begin{array}{c}663.2 \\
98\end{array}$ & $\begin{array}{c}926.03 \\
1\end{array}$ & $\begin{array}{c}788.4 \\
19 \\
\end{array}$ & $\begin{array}{c}841.0 \\
08 \\
\end{array}$ & S.D. \\
\hline & & $\begin{array}{l}\text { Estimación } \\
\text { HPE }\end{array}$ & & 2.709 & 2.829 & 3.060 & 3.265 & 3.593 & S.D. \\
\hline \multirow[t]{3}{*}{$\begin{array}{c}\text { As } \\
\text { Somozas }\end{array}$} & \multirow[t]{3}{*}{3} & $\begin{array}{l}\text { Produción } \\
\text { (MWh) }\end{array}$ & & & & 6.587 & 7.492 & 7.843 & 6.943 \\
\hline & & $\begin{array}{l}\text { Estim. } \\
\text { Facturac. }(€)\end{array}$ & & & & $\begin{array}{c}664.53 \\
5 \\
\end{array}$ & $\begin{array}{c}603.1 \\
08\end{array}$ & $\begin{array}{c}611.8 \\
76\end{array}$ & $\begin{array}{c}606.5 \\
60\end{array}$ \\
\hline & & $\begin{array}{l}\text { Estimación } \\
\text { HPE }\end{array}$ & & & & 2.196 & 2.497 & 2.614 & 2.314 \\
\hline \multirow[t]{3}{*}{ Arbo } & \multirow[t]{3}{*}{2,7} & $\begin{array}{l}\text { Produción } \\
\text { (MWh) }\end{array}$ & & & & 6.707 & 6.831 & 7.745 & 6.788 \\
\hline & & $\begin{array}{l}\text { Estim.Facturac } \\
.(€)\end{array}$ & & & & $\begin{array}{c}676.64 \\
1 \\
\end{array}$ & $\begin{array}{c}549.8 \\
97 \\
\end{array}$ & $\begin{array}{c}604.2 \\
31 \\
\end{array}$ & $\begin{array}{c}593.0 \\
19 \\
\end{array}$ \\
\hline & & $\begin{array}{l}\text { Estimación } \\
\text { HPE }\end{array}$ & & & & 2.484 & 2.530 & 2.869 & 2.514 \\
\hline \multirow[t]{3}{*}{ As Neves } & \multirow[t]{3}{*}{2,4} & $\begin{array}{l}\text { Produción } \\
\text { (MWh) }\end{array}$ & & & & & & 6.302 & 5.173 \\
\hline & & $\begin{array}{l}\text { Estim. } \\
\text { Facturac. }(€)\end{array}$ & & & & & & $\begin{array}{c}491.6 \\
54 \\
\end{array}$ & $\begin{array}{c}451.9 \\
28 \\
\end{array}$ \\
\hline & & $\begin{array}{l}\text { Estimación } \\
\text { HPE }\end{array}$ & & & & & & 2.626 & 2.155 \\
\hline \multirow[t]{3}{*}{ Arteixo } & \multirow[t]{3}{*}{2} & $\begin{array}{l}\text { Produción } \\
\text { (MWh) }\end{array}$ & & & & & & & 4.306 \\
\hline & & $\begin{array}{l}\text { Estim. } \\
\text { Facturac. }(€)\end{array}$ & & & & & & & $\begin{array}{c}376.1 \\
84 \\
\end{array}$ \\
\hline & & $\begin{array}{l}\text { Estimación } \\
\text { HPE }\end{array}$ & & & & & & & 2.153 \\
\hline
\end{tabular}

Fonte: Elaboración propia a partir de DOG, METAD, CNMC. *S.D.: sen dato.

Revista Galega de Economía: http:/ / www.usc.es/ econo/ RGE/ benvidag.htm 